\title{
A New Multichelating Acid System for High-Temperature Sandstone Reservoirs
}

\author{
Nianyin Li, Qian Zhang, Yongqing Wang, Pingli Liu, and Liqiang Zhao \\ State Key Lab of Oil and Gas Reservoir Geology and Exploitation, South West Petroleum University, Chengdu, Sichuan 610500, China \\ Correspondence should be addressed to Nianyin Li; linianyin@swpu.edu.cn
}

Received 2 November 2014; Accepted 2 January 2015

Academic Editor: Ming Huo

Copyright (C) 2015 Nianyin Li et al. This is an open access article distributed under the Creative Commons Attribution License, which permits unrestricted use, distribution, and reproduction in any medium, provided the original work is properly cited.

\begin{abstract}
Sandstone reservoir acidizing is a complex and heterogeneous acid-rock reaction process. If improper acid treatment is implemented, further damage can be induced instead of removing the initial plug, particularly in high-temperature sandstone reservoirs. An efficient acid system is the key to successful acid treatment. High-temperature sandstone treatment with conventional mud acid system faces problems including high acid-rock reaction rate, short acid effective distance, susceptibility to secondary damage, and serious corrosion to pipelines. In this paper, a new multichelating acid system has been developed to overcome these shortcomings. The acid system is composed of ternary weak acid, organic phosphonic chelating agent, anionic polycarboxylic acid chelating dispersant, fluoride, and other assisted additives. Hydrogen ion slowly released by multistage ionization in ternary weak acid and organic phosphonic within the system decreases the concentration of HF to achieve retardation. Chelating agent and chelating dispersant within the system inhibited anodic and cathodic reaction, respectively, to protect the metal from corrosion, while chelating dispersant has great chelating ability on iron ions, restricting the depolarization reaction of ferric ion and metal. The synergic effect of chelating agent and chelating dispersant removes sulfate scale precipitation and inhibits or decreases potential precipitation such as $\mathrm{CaF}_{2}$, silica gel, and fluosilicate. Mechanisms of retardation, corrosion-inhibition, and scale-removing features have been discussed and evaluated with laboratory tests. Test results indicate that this novel acid system has good overall performance, addressing the technical problems and improving the acidizing effect as well for high-temperature sandstone.
\end{abstract}

\section{Introduction}

Sandstone matrix acidizing is one of the essential technical strategies to maintain or increase the productivity of hydrocarbon wells or the injectivity of water injectors. With the flow and reaction of acid in intergranular porosity and cavity, the near wellbore region damaged by drilling, completion, workover, or injection of water can be removed to recover or increase the production. The acid-rock reaction in sandstone matrix is a fairly complex process, including the chemical reaction between a variety of minerals and hydrofluoric acid, which happens most in porous media, and is considered as multiphase "heterogeneity" reaction. Since there are different minerals reaction rate with acids and difficulty in measurement, the reaction process is beyond accurate prediction. Therefore, improper acidizing treatment not only cannot remove the original plugs, but also bring further damage to reservoir [1-5].
Stimulation effect is highly dependent on acid systems. To implement a successful acid treatment, an optimized acid system considering the formation characteristics and the function and performance of both acids and additives should be applied to meet requirements of the treatment.

In high temperature conditions, regular mud acid reacts rapidly, with limited effective distance, and untouched to the deep reservoir. Moreover, regular mud acid could induce massive secondary precipitation and heavy corrosion on downhole tubulars and devices. Corrosion inhibitors have been used with acids for decades but their function is limited in some extreme conditions, especially under high temperature circumstances. Corrosion inhibitors can be classified into 5 categories: amino polycarboxylic type, hydroxy carboxylic type, amino type, organic phosphate type, and polycarboxylic type. The first use of chelating agent was to dissolve carbonate in 1973 [6]. And in 1985, Tyler et al. first used EDTA in sandstone reservoir [7]. Several of researches 
have proved the great advantage of chelating agent in acid treatment of sandstone reservoir, leading to wide use like EDTA, HEDTA, NTA, and so forth [8]. Al-Harbi et al. introduced the application of chelating agents to sandstone acid systems in 2013 [9]. For acidizing treatment in hightemperature sandstone reservoir, chelating agents use is the future for improving treatment effectively [10-17]. Due to the limitations of pros and cons of single chelating agent usage, this paper introduces a synergic affected optimized mixture of chelating agent and dispersant, a high-temperature multichelating acid system with satisfactory effect on retardation, corrosion inhibition, scale inhibition, and scale removing through careful designs and detailed characteristic evaluation.

\section{Design of High Temperature Multichelating Acid System}

The multichelating acid system consists of $\mathrm{H}_{3} \mathrm{PO}_{4}, \mathrm{SAV}-1$, $\mathrm{SAV}-2, \mathrm{NH}_{4} \mathrm{~F}$, and additives, with the organic phosphonic chelating agent SAV-1 and the anionic poly carboxylic acid chelating dispersant SAV-2. Using the weak acid to slow the releasing rate of hydrogen ion can decrease the $\mathrm{HF}$ concentration for retardation. Chelating agents and dispersants are utilized to prevent or decrease the generation of secondary precipitation. Even though floating particles and partial insoluble precipitation are formed, dispersant agent could distribute them in the reacted acid steadily, reducing the possibility of precipitating and plugging (the particular feature also possesses fine rate of metallic corrosion). $\mathrm{pH}$ value can be controlled within a certain range by using buffer solution, thus decreasing the amount of secondary precipitation.

The molecular structure of SAV-1 is as shown in Figure 1.

The molecular structure of SAV-2 is as shown in Figure 2.

\section{Evaluation on Overall Performance of Multichelating Acid}

\subsection{Retardation Mechanism and Performance Evaluation}

3.1.1. Retardation Mechanism. (1) The main function body of hydrofluoric acid is to unionize HF molecule instead of ionized $\mathrm{F}^{-}$or $\mathrm{HF}^{2-}$, and surface reaction is the affinity chemisorption of unionized HF molecule and aluminum silicate mineral lattice bond, rather than simply the substitution or generation of hydrogen bond $[18,19]$.

The consumption of hydrogen ions is fast, leading to a sharp rise of $\mathrm{pH}$ value, which results in hydrofluoric acid affected near borehole area only without further displacement into the formation. SAV-1 and SAV-2 in this claimed system gradually ionize hydrogen ions, and the post production can form a buffer solution to control $\mathrm{pH}$ value within a certain range to achieve retardation.

(2) Regular acid would be mostly consumed on clay surface for it is larger than other minerals', which causes ineffectively utilization of acid as well as destruction of rock framework.

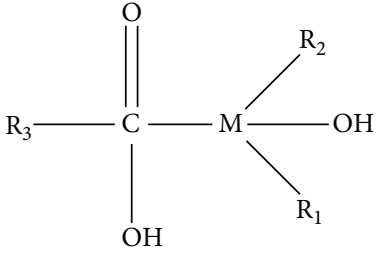

FIgURe 1: Molecular structure of SAV-1.<smiles>NOI</smiles>

FIGURE 2: Molecular structure of SAV-2.

Due to the physical and chemical absorption effects of the multichelating acid, SAV-1 reacts easily with clay and fillers with higher calcium, iron, aluminum component, forming a thin film on clay surface, which can not only promote deeper acidizing but also maintain the integrity of rock framework. The thin film is less than $1 \mu \mathrm{m}$ under SEM observation, with low solubility in weak acid and water but high dissolving rate in $\mathrm{HCl}$, and it can retard the rapid reaction of clay and acid.

Figure 3 is the SEM comparison between montmorillonites before and after pictures with mud acid and multichelating acid. The results indicate that when reacted with multichelating acid for 5 minutes, a thin film was formed on the clay surface, which phenomena had not been seen from the mud acid experiment with montmorillonites.

(3) The addition organic phosphonic acid is an anionic phosphonate with a prominent feature of strong waterwettability. This feature may catalyze the reaction between fluorinated acid and quartz, making the initial low dissolving rate of quartz increased high as time extends, which is helpful to radial permeability improvement of deep formation. Researches demonstrate that this above acid treated clay mineral is agglomerated in toluene and easily dispersed in methanol, which indicates that the water-wet surface will not have bad effect on the reservoir and production of oil and gas development.

3.1.2. Evaluation on Retardation Performance. Mud acid $(9 \% \mathrm{HCl}+1.5 \% \mathrm{HF})$ and multichelating acid $\left(5 \% \mathrm{H}_{3} \mathrm{PO}_{4}+\right.$ $4 \%$ SAV- $1+1 \%$ SAV-2 $+1.5 \% \mathrm{NH}_{4} \mathrm{~F}$ ) were used to react with sandstone minerals, whose composition was 35\% quartz, $14 \%$ potassium feldspar, $13 \%$ albite, $6 \%$ dolomite, $2 \%$ kaolinite, 9.5\% chlorite, $1 \%$ Illite, and $1.5 \%$ montmorillonite. Experiment temperature was $95^{\circ} \mathrm{C}$, with $1 \mathrm{~g} / 10 \mathrm{~mL}$ solid-liquid ratio. The experiment results showed that the multichelating acid dissolving rate was far lower than that of mud acid in the early stage, while the dissolution rate of mud acid slightly changed and that of multichelating acid was gradually increased as time went on. After 4 hours of reaction, the dissolution rate of the multichelating acid was nearly equal to that of mud acid, which indicated the better retardation ability of multichelating acid. Therefore, the good retardation performance of multichelating acid prolongs the acid active 


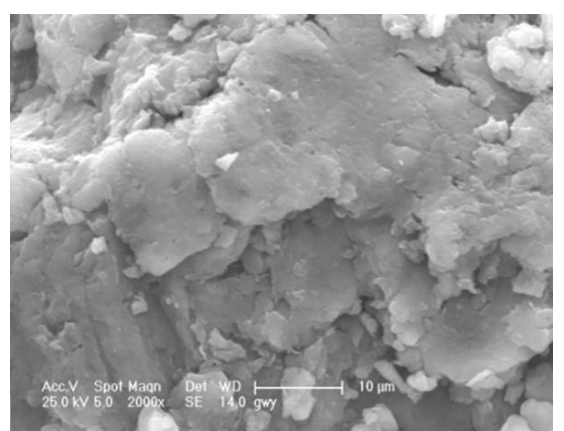

(Montmorillonite)

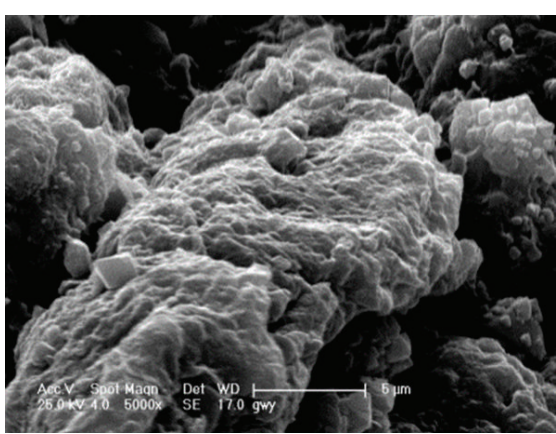

(Reacted with chelating acid)

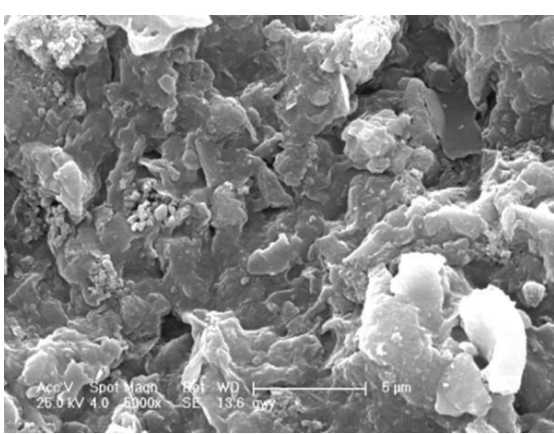

(Reacted with mud acid)

FIGURE 3: SEM of montmorillonite after the reaction with acid.

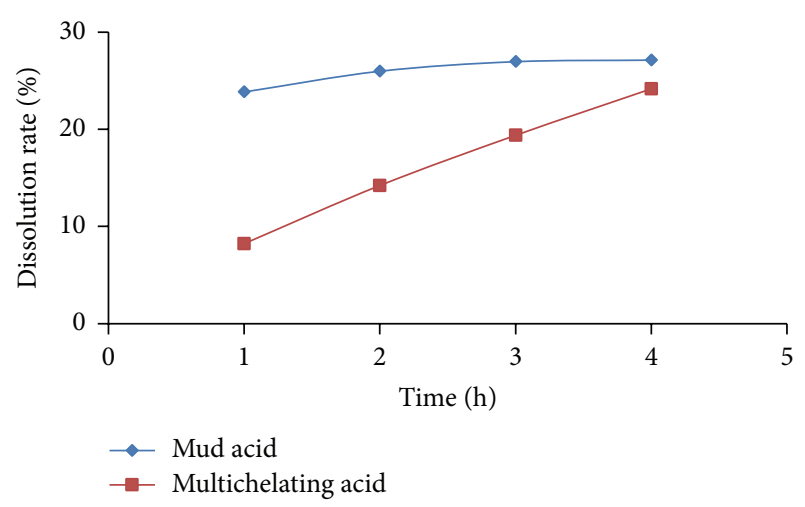

FIGURE 4: Rock-powder dissolving rate with mud acid and multichelating acid.

reaction time and extends the effective distance of acidizing. The results are shown in Figure 4.

3.2. Corrosion Inhibition Mechanism and Performance Evaluation. Under high temperature condition, the corrosion rate of acid directly affects the safety of acidizing treatment. The hydroxyl of SAV-1 molecule, where oxygen atom can form coordinate bond with iron ion or partially positivecharged iron atom on the iron surface because of unshared electron pair, thus forms an absorption precipitation layer. The layer covers the iron surface, preventing the diffusion of dissolved oxygen to the metal. Since precipitation membrane is more likely to form in alkaline environment, it inhibits the electrochemical corrosion of the cathodic reaction for $\mathrm{OH}^{-}$ ion generated faster on local cathode area of the precipitation membrane [20, 21]. Additionally, the extended methyl in SAV-1 to the outside of the membrane prevents the diffusion of dissolved oxygen to the metal and protects the mental from corrosion more effectively.

SAV-2 is a water-soluble polypeptide chain, elongated by peptide bond (-CO-NH-). There are quite many polar groups, including carboxyl, carbon, and amino. The oxygen and nitrogen atoms in peptide contain plenty of lone pair electrons. The oxygen atoms in peptide involve $\pi$ bond, absorbing with $\mathrm{d}$ atomic orbital and resulting in directional arrangement of these polar groups on metal surface. However, the nonpolar groups produce great steric hindrance and impede the reduction reaction on cathode by diffusion of $\mathrm{O}_{2}$ and hence restrict the corrosion of anodic metal. Besides, SAV-2 has a strong chelating ability over many metal ions including ferric ion, decreasing the corrosion caused by depolarization reaction.

Table 1 lists the corrosion rate of steel, without corrosion inhibition agent, of multichelating acid and regular mud acid. The result shows that corrosion rate of mud acid is approximately 10 times of that with multichelating acid, which demonstrating the latter has better corrosion inhibition ability, decreasing the risk of treatment in hightemperature reservoir and lowering the demand for corrosion inhibition agent.

\subsection{Scale Removing Mechanism and Performance Evaluation}

3.3.1. Sulfate Scales Inhibiting/Removing Mechanism and Performance Evaluation of Multichelating Acid System. Carbonate scale can be easily removed by $\mathrm{HCl}$, leaving sulfate scale to be the key technical problem. There are three steps during the growth and sedimentation of $\mathrm{CaSO}_{4}$ crystal, the process of forming oversaturated solutions: the generating of crystal nucleus, the growing of crystal nucleus, and the forming of crystal. Once any step is broken, the forming of scale would be inhibited or slowed down. The function of inhibitor is to control one or several steps to prevent precipitation. Compared with other acids, multichelating acid has advantage in precipitation inhibiting and removing ability.

(1) Lattice Distortion. In the growth of crystal, there exists vacancy, dislocation, and other lattice defect, or embedded structure distortion with the changing of external condition [22]. Each crystal plane develops unevenly in a single lattice. The spatial difference in crystal makes the crystal unstable and easy to break when the environment changes. The external reason can be mechanical failure and variation of oversaturation, but most importantly the change of chemical environment. $\mathrm{CaSO}_{4}$ contains ionic lattice, whose growth follows strict sequence. Only when a positive $\mathrm{Ca}^{2+}$ collides with negative $\mathrm{SO}_{4}{ }^{2-}$ from another atom, the combination could happen. Therefore, $\mathrm{CaSO}_{4}$ scale is hard scale with 
TABLE 1: Comparison of corrosion rate of multichelating acid and conventional mud acid.

\begin{tabular}{|c|c|c|}
\hline & $9 \% \mathrm{HCl}+1.5 \% \mathrm{HF}$ & $5 \% \mathrm{H}_{3} \mathrm{PO}_{4}+4 \% \mathrm{SAV}-1+1 \% \mathrm{SAV}-2+1.5 \% \mathrm{NH}_{4} \mathrm{~F}$ \\
\hline Before corrosion & & (1) \\
\hline After corrosion & & \\
\hline Corrosion rate $\left(\mathrm{g} / \mathrm{m}^{2} \cdot \mathrm{h}\right)$ & 586.75 & 53.92 \\
\hline Conditions & \multicolumn{2}{|c|}{ Temperature: $120^{\circ} \mathrm{C}$; time: $4 \mathrm{~h}$} \\
\hline
\end{tabular}

certain direction and strictly sequential arrangement. Scaleinhibitor is absorbed on crystal, adulterating inside cell lattice, occupying the active point in polymer, which leads to a more serious distortion in the crystal further growth. Or inner stress raises, and large and irregular amorphous particle is formed, thus making the crystal easy to break, and growth is obstructed.

By comparing the SEM photos before and after the addition of SAV-1/SAV-2, an apparent shape change in crystal can be observed. Before adding SAV-1/SAV-2, the $\mathrm{CaSO}_{4}$ crystal had sharp edges in regular form with smooth surface, where thin bands of crystal were arranged in a tight and ordered way (as shown in Figure 5). After adding SAV-1/SAV2 , the crystal form changed significantly, which had irregular form with shorter length, rough surface, and loose and disorderly arrangement; in addition, minor cracks appeared. The crystal experienced a serious distortion (as shown in Figure 6).

(2) Chelating Solubility. Crystallization is a phase transition process developed in the system microdomain. Besides electrostatic force, oversaturation of crystal material exists as reaction force. Crystallization can be divided into two steps: generation and growth of crystal nucleus. And the addition of inhibitor affects both processes.

SAV-2 structure formula mainly contains $-\mathrm{COOH}$ and NHCO- functional groups, a liner polymeric scale inhibitor with concentration and anion characteristics. SAV-2 can form a stable chelate with $\mathrm{Ca}^{2+}$ in water, thus lowering the oversaturation level of $\mathrm{CaSO}_{4}$ and inhibiting formation of scale. Figure 7 is the sketch of this reaction.

SAV-1 dissociates $\mathrm{H}^{+}$and negatively charged phosphate group, $-\mathrm{PO}(\mathrm{OH})_{2}$, from water, and the latter group provides coordinate electron for $\mathrm{Ca}^{2+}$ on $\mathrm{CaSO}_{4}$ surface lattice, constituting chelate with a hexatomic ring. The chelate product has better solubility than that of calcium and magnesium salt; thus calcium and magnesium ions are stabilized in high concentrated chelate-bearing water, inhibiting scale deposition. The hexatomic ring structure formed by SAV-1 and $\mathrm{Ca}^{2+}$ is shown in Figure 8.

Also, the acid radical negative anion can react with the $\mathrm{Ca}^{2+}$ in formed crystals, making $\mathrm{CaSO}_{4}$ microcrystals hard to arrange in strict lattice orders during collision process; therefore large crystal is uneasy to form. Since solubility is improved for the remaining small grain range of crystals, the multichelating acid also inhibits $\mathrm{CaF}_{2}$ secondary precipitation effectively based on the same mechanism.

(3) Electrostatic Interaction. SAV-1/SAV-1 dissociates polyaspartic ion, organic phosphonic ion, and hydrogen ion from water, the nitrogen atoms in these acid radical anion and molecule, plus the oxygen atom in carboxyl and phosphine group, resulting in gathered potential scaling microcrystals and repulsed to each other due to the same negative charge (as shown in Figure 9). Therefore, the collision among, the formation of large crystals, the conduction between microcrystals and metal transmission surface and the formation and growth of scale have all been hindered.

$\mathrm{X}$-ray diffusion (XRD) is another effective way to study the growth of crystal. When electron rays beams illuminate on a sample, the components trigger multiple X-rays with corresponding features. Among these emitted rays, angles exist between the X-rays and crystal surface satisfying the Prague diffraction condition. The comparison of the diffraction intensity, variation of diffraction angle, crystal axis and other parameters of the scaling samples' X-ray diffraction diagrams, indicating the variations in the degree of fragment, degree of distortion and crystal system with or without scaling inhibitor $[23,24]$. Figures 10 and 11 show the XRD diagrams before and after adding SAV-1/SAV-2 into the $\mathrm{CaSO}_{4}$ scale.

Generally, there are three forms of $\mathrm{CaSO}_{4}$ scale: gypsum (calcium sulfate carrying two crystalline water particles), calcium sulfate hemihydrate, and anhydrous calcium sulfate. Comparing Figures 10 and 11 with standard XRD diagram, it is certain that crystal type of both samples is gypsum, which belongs to monoclinic system.

It can be spotted from the figures that the diffraction angles before and after adding SAV-1/SAV-2 are almost the same (shown in Table 2), but at some certain diffraction angles the X-rays' relative intensity has changed. After adding SAV-1/SAV-2, the unit cell constant has ascended compared with the straight calcium sulfate (shown in Table 3). The enlargement of unit cell size also demonstrates the entre of SAV-1/SAV-2 or absorption on the crystal surface in crystallization of calcium sulfate, which makes the unit cells 


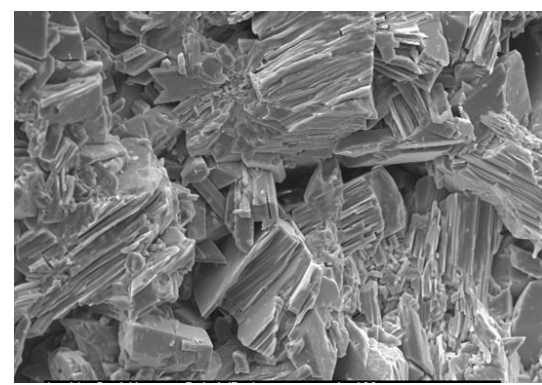

$200 \mathrm{x}$

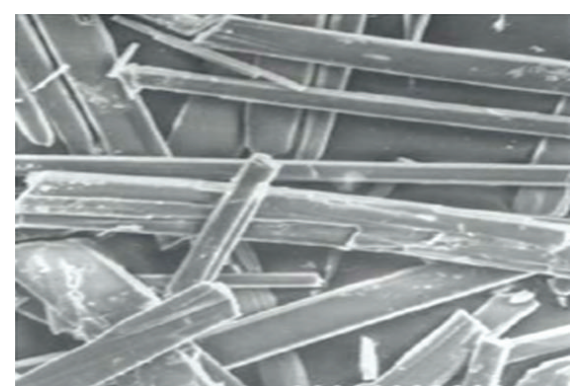

$700 \mathrm{x}$

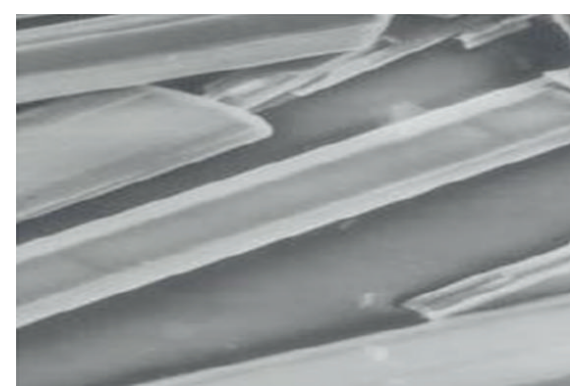

$1000 x$

FIGURE 5: Plank and pillar-like gypsum crystal before SAV-1/SAV-2 treatment. *Annotation: 200x, 700x, and 1000x are the magnification under observation.

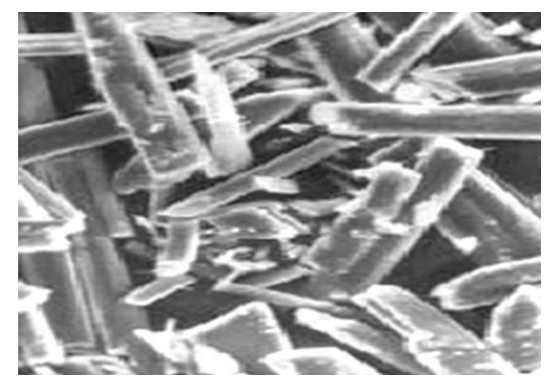

Chaotic

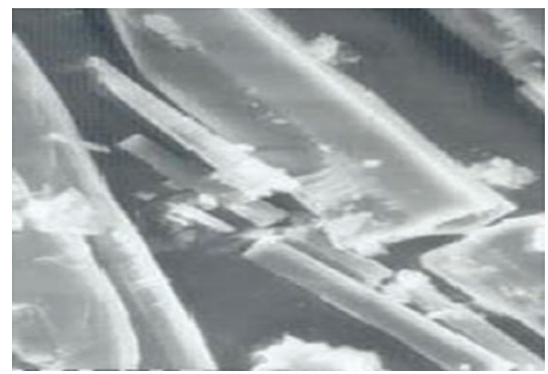

Broken

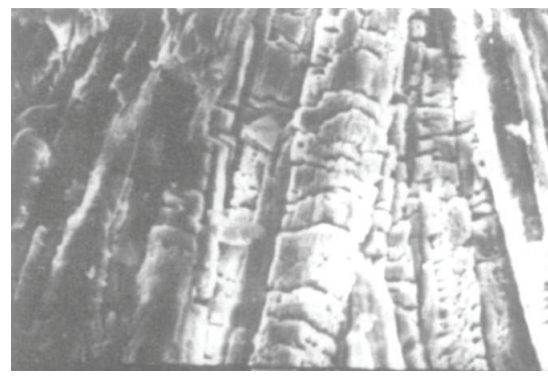

Cracks

FIGURE 6: Plank and pillar-like gypsum crystal after SAV-1/SAV-2 treatment.

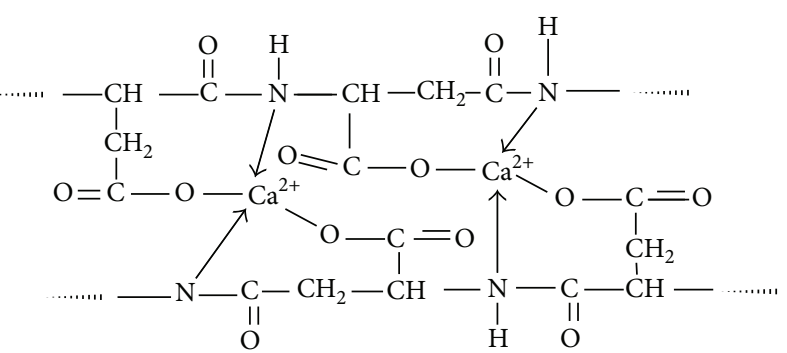

FIGURE 7: Chelating reaction of SAV-2 and $\mathrm{Ca}^{2+}$.<smiles>CC(O)P1(=O)O[Te]C[18O]P1(=O)O</smiles>

Figure 8: Chelating reaction of SAV-1 and $\mathrm{Ca}^{2+}$.

of calcium sulfate accumulate in an irregular way; thus different forms are observed.

Based on crystallization spiral dislocation theory [25], the points of increasing activity are limited, and when dislocation occurs after active points react with scale-inhibited agent, continuous growth is obstructed. Hence, even a low concentration of scale-inhibiting agent can inhibit the generating of crystal, thus inhibiting the formation of $\mathrm{CaSO}_{4}$.

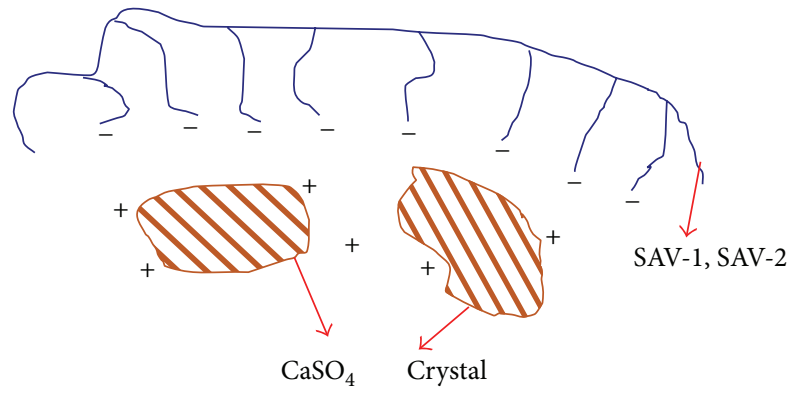

FIGURE 9: Intercrystalline electrostatic repelling effect.

\subsubsection{Silica Gel Precipitation Inhibition Mechanism and Performance Evaluation}

\section{(1) Mechanism of Inhibiting Silica Gel Precipitation}

(a) Effects on Surface Properties of Silicon Polymers. Due to physical or chemical effects, scale inhibiting dispersing agent after ionization into anionic will obtain strong absorptive capability. The anions are absorbed on the surface of silicon polymers, changing the physical and chemical properties of silicon polymers' surface, making them acquire same negative charges and causing mutual electrostatic repulsion between particles. These reactions avoid accumulated growth of silicon polymers, suspend disperse particles in water, and 
TABLE 2: Comparisons of diffraction data of $\mathrm{CaSO}_{4} \cdot 2 \mathrm{H}_{2} \mathrm{O}$.

\begin{tabular}{lcccccc}
\hline & Peak number & $D\left(10^{-10} \mathrm{~m}\right)$ & $2 \theta$ & $h$ & $l$ \\
\hline \multirow{3}{*}{ Straight crystal } & 1 & 7.58121 & 11.6731 & 0 & 2 & 0 \\
& 2 & 4.2811 & 20.7488 & 1 & 2 & 1 \\
\hline \multirow{3}{*}{ After treatment of SAV-1/SAV-2 } & 4 & 3.06593 & 29.127 & 0 & 0 & 2 \\
& 1 & 7.61214 & 11.6762 & 0 & 2 & 0 \\
& 2 & 4.32105 & 20.7504 & 1 & 2 & 1 \\
\hline
\end{tabular}

TABLE 3: Unit cell constant of $\mathrm{CaSO}_{4} \cdot 2 \mathrm{H}_{2} \mathrm{O}$.

\begin{tabular}{lccc}
\hline Samples & $a\left(10^{-10} \mathrm{~m}\right)$ & $b\left(10^{-10} \mathrm{~m}\right)$ & $c\left(10^{-10} \mathrm{~m}\right)$ \\
\hline Standard & 5.68 & 15.18 & 6.51 \\
Straight & 5.67 & 15.13 & 6.51 \\
After treatment of SAV-1/SAV-2 & 5.71 & 15.27 & 6.54 \\
\hline
\end{tabular}

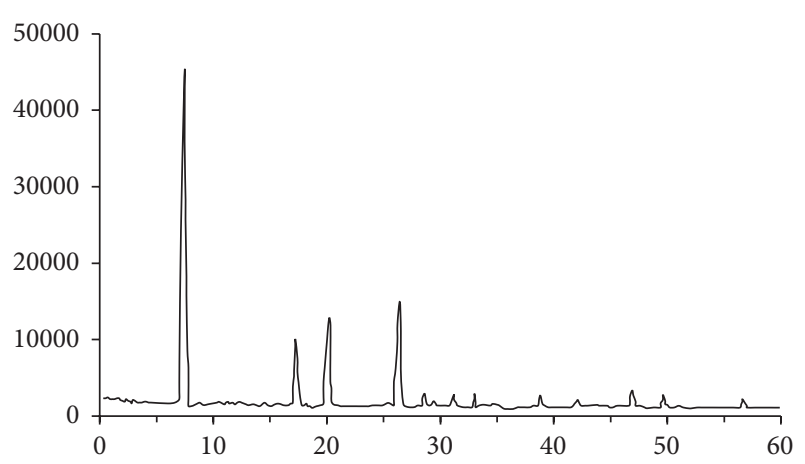

FIGURE 10: XRD diagram before adding SAV-1/SAV-2.

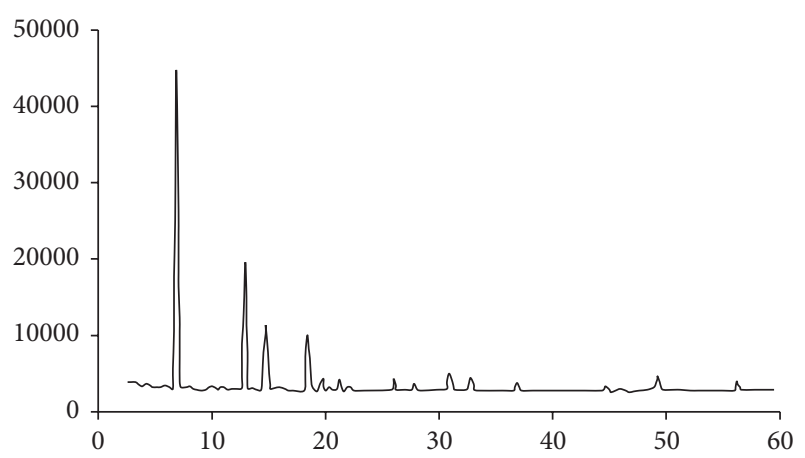

FIGURE 11: XRD diagram after adding SAV-1/SAV-2.

block the silicon polymerization from single to dimer or multimer [26]. Meanwhile, with the negatively charged inhibiting dispersant scale agent absorbed on silicon polymers surface, silicon polymers are unlikely to form silicate scales by losing water with the enhanced hydrophilic.

(b) Dispersion Effects on Silicon Polymers. When an anion of scale inhibitor dispersing agent absorbs one or more silicon polymers, same electronic charge as the anion is with electrostatic repulsion, which prevents collision and the formation of polymers. It is known as flocculation of polymer anion and crystalloid particles, which makes crystalloid be absorbed on polymer chains and also gathers the potential scaling crystalloids to a certain extent [27]. When the products of absorption meet other copolymer molecules or diffuse to a relatively high concentration of polymers area, they offer the absorbed particles to other polymer molecules and finally form a state of balance. This is the dispersion effect on flocculated crystalloids by polymer anion. By such effect of flocculation and dispersion, silicon polymers could keep suspension in aqueous solution stably.

(2) Evaluation of Scale Inhibition Capability. Using $\mathrm{Na}_{2} \mathrm{SiO}_{3}$ $.9 \mathrm{H}_{2} \mathrm{O}$ to prepare $2 \mathrm{kinds}$ of solution during the experiments as comparison (Solution 1, the concentration of silicon ion is $4000 \mathrm{mg} / \mathrm{L}$, containing $1.5 \mathrm{~mL} \mathrm{SAV-1}$ and $0.5 \mathrm{~mL} \mathrm{SAV-2}$; Solution 2, the concentration of silicon ion is $2000 \mathrm{mg} / \mathrm{L}$ without chelating agent), volumes of both solutions are $50 \mathrm{~mL}$, with $2.5 \mathrm{pH}$ value. These two kinds of solutions were heated in water bath under $95^{\circ} \mathrm{C}$; after cooling down and filtering, molybdenum blue photometric method was used to measure the content of silicon ion and weight method was used to measure the amount of silica gel precipitate. The results are shown in Table 4.

The results in Table 4 demonstrate the great inhibiting capability of chelating agent of the formation of silica gel precipitate. Moreover, by comparing the standard silicon ion solution before and after chelating agent addition (as shown in Figure 12), observation shows that the sample precipitates a lot after 30 minutes of heating without chelating agent, and the amount of precipitation increases with the heating time. However, though the sample with chelating agent has a high concentration of silicon ion, the solution still remains transparent after 90 minutes of heating. Precipitate appears after heating for 120 minutes and becomes turbid.

3.3.3. Mechanism of Inhibiting Fluosilicate Precipitation. When sandstone reservoir is treated by HF acid system or other acid systems where HF is produced during the process, the primary reaction between $\mathrm{HF}$ and aluminosilicate produces fluosilicic acid, whose reaction with $\mathrm{Na}^{+}, \mathrm{K}^{+}, \mathrm{Ca}^{2+}$ 


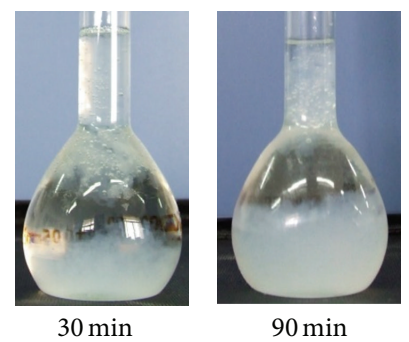

(No chelating agent)

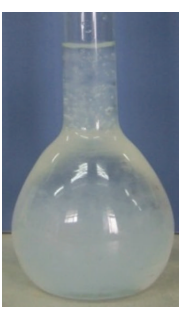

$120 \mathrm{~min}$

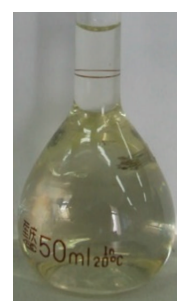

$30 \mathrm{~min}$

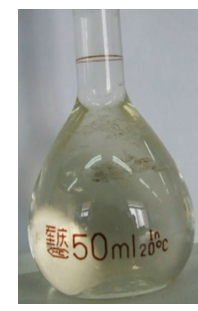

$90 \mathrm{~min}$

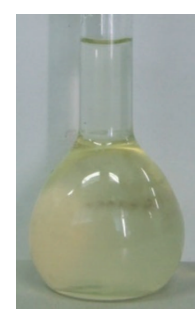

$120 \mathrm{~min}$

(Chelating agent added)

FIGURE 12: Comparison of chelating agent added before and after in Si ion standard solution.

TABLE 4: Chelating agent's effect on silica gel precipitate.

\begin{tabular}{|c|c|c|c|c|c|c|}
\hline \multirow[b]{2}{*}{ Sample } & \multicolumn{2}{|c|}{$30 \mathrm{~min}$} & \multicolumn{2}{|c|}{$90 \mathrm{~min}$} & \multicolumn{2}{|c|}{$120 \mathrm{~min}$} \\
\hline & $\begin{array}{l}\text { Concentration of } \\
\qquad \mathrm{Si}(\mathrm{mg} / \mathrm{L})\end{array}$ & $\begin{array}{c}\text { Amount of silica } \\
\text { gel precipitate } \\
(\mathrm{mg})\end{array}$ & $\begin{array}{l}\text { Concentration of } \\
\text { Si }(\mathrm{mg} / \mathrm{L})\end{array}$ & $\begin{array}{c}\text { Amount of silica } \\
\text { gel precipitate } \\
(\mathrm{mg})\end{array}$ & $\begin{array}{l}\text { Concentration of } \\
\qquad \mathrm{Si}(\mathrm{mg} / \mathrm{L})\end{array}$ & $\begin{array}{c}\text { Amount of silica } \\
\text { gel precipitate } \\
\text { (mg) }\end{array}$ \\
\hline $\begin{array}{l}\text { No chelating agent } \\
(2000 \mathrm{mg} / \mathrm{L})\end{array}$ & 1243.12 & 129.48 & 765.29 & 211.22 & 586.44 & 241.82 \\
\hline $\begin{array}{l}\text { Chelating agent } \\
\text { added } \\
(4000 \mathrm{mg} / \mathrm{L})\end{array}$ & 3810.63 & 32.39 & 3613.13 & 66.18 & 3020.63 & 167.54 \\
\hline
\end{tabular}

in formation water caused reservoir damage by generated silicofluoride precipitation. The mechanism of silicofluoride precipitation inhibition by multichelating agent is basically the same as that of silica gel precipitation inhibition. Generally speaking, organic phosphonic acid has better absorption capability than polycarboxylate acid on crystalloid surface, with a relatively poor dispersion capability. Therefore, by combining chelating agent and chelating dispersant, the inhibition effect on potassium (or sodium) fluorosilicate crystallization can be enhanced, improving scale inhibiting effect $[28,29]$.

To evaluate the effect of acid on silicofluoride precipitation inhibition, scale inhibiting effect evaluation experiments were conducted [30].

Four kinds of solutions were prepared for comparison experiments: Solution 1: concentration of $\mathrm{Na}^{+}$is $0.25 \mathrm{~mol} / \mathrm{L}$ (or concentration of $\mathrm{K}^{+}$is $0.25 \mathrm{~mol} / \mathrm{L}$ ), and concentration of fluosilicic acid is $0.25 \mathrm{~mol} / \mathrm{L}$, no scale inhibitor contained. Solution 2: concentration of $\mathrm{Na}^{+}$is $0.25 \mathrm{~mol} / \mathrm{L}$ (or concentration of $\mathrm{K}^{+}$is $0.25 \mathrm{~mol} / \mathrm{L}$ ), and concentration of fluosilicic acid is $0.25 \mathrm{~mol} / \mathrm{L}$, containing $12.5 \mathrm{~mL}$ inhibitor SAV-1 $(10 \mathrm{mg} / \mathrm{mL})$. Solution 3: concentration of $\mathrm{Na}^{+}$is $0.25 \mathrm{~mol} / \mathrm{L}$ (or concentration of $\mathrm{K}^{+}$is $0.25 \mathrm{~mol} / \mathrm{L}$ ), and concentration of fluosilicic acid is $0.25 \mathrm{~mol} / \mathrm{L}$, containing $12.5 \mathrm{~mL}$ inhibitor SAV-2 $(10 \mathrm{mg} / \mathrm{mL})$. Solution 4 : concentration of $\mathrm{Na}^{+}$is $0.25 \mathrm{~mol} / \mathrm{L}$ (or concentration of $\mathrm{K}^{+}$is $0.25 \mathrm{~mol} / \mathrm{L}$ ), and concentration of fluosilicic acid is $0.25 \mathrm{~mol} / \mathrm{L}$, containing $12.5 \mathrm{~mL}$ mixed inhibitor of SAV-1 $(5 \mathrm{mg} / \mathrm{mL})$ and SAV-2 $(5 \mathrm{mg} / \mathrm{mL})$.

Stainless steel pieces were immersed in beakers filled with $1000 \mathrm{~mL}$ of the four solutions separately. After 12 hours of heating in water bath at $50^{\circ} \mathrm{C}$, those pieces were taken out, dried, and weighted.
TABLE 5: Experimental results of scale inhibitor on the inhibition of sodium fluosilicate precipitation.

\begin{tabular}{lcc}
\hline Scale inhibitor & Scale weight $(\mathrm{g})$ & $\begin{array}{c}\text { Scale inhibition ratio } \\
(\%)\end{array}$ \\
\hline Comparing sample & 0.1742 & - \\
SAV-1 & 0.1536 & 11.81 \\
SAV-2 & 0.0582 & 67.57 \\
SAV-1 + SAV-2 (1:1) & 0.0632 & 63.74 \\
\hline
\end{tabular}

Formulation of the scale inhibition ratio is as follows:

$$
\eta=\frac{G_{1}-G_{2}}{G_{1}} \times 100 \%
$$

In this formulation, $G_{1}$ is the weight of stainless steel piece without scale inhibitor addition (g); $G_{2}$ is the weight of stainless steel piece with scale inhibitor addition $(\mathrm{g}) ; \eta$ is the scale inhibition ratio (\%).

Table 5 indicates that SAV-2 or the mixture of SAV-1 and SAV-2 has relatively strong inhibiting capability to fluosilicate precipitation.

\section{Conclusion}

(1) The concentration of unionized HF could be reduced to achieve retardation by decreasing the concentration of $\mathrm{H}^{+}$in acid; the use of synergic method of chelation and dispersion could prevent/reduce the generation of secondary precipitation; $\mathrm{pH}$ value controlled at a certain range with 
buffer solution could partially decrease secondary precipitation; therefore a new acid system is devised: $\mathrm{H}_{3} \mathrm{PO}_{4}+\mathrm{SAV}-1$ $+\mathrm{SAV}-2+\mathrm{NH}_{4} \mathrm{~F}$.

(2) Experiments indicate that chelating acid has good performance on retardation and dissolution capability. $\mathrm{H}_{3} \mathrm{PO}_{4}$ and SAV-1 can slowly ionize $\mathrm{H}^{+}$; meanwhile the reactant of SAH and SAV-1 can function as buffer solution, which controls $\mathrm{pH}$ value and $\mathrm{HF}$ concentration within a certain range to achieve retardation. SAV-1 in acid slows the reaction rate by chemical and physical absorption.

(3) It has been verified that high temperature multichelating acid shows great corrosion inhibition performance, and a few corrosion inhibitors could meet the requirement of acidizing treatment. SAV-1 is a cathodic corrosion inhibitor, mainly focusing on inhibiting cathodic corrosion, while SAV2 is able to impede the anodic corrosion, and there exists associated corrosion inhibition effect of these two.

(4) The chelating agents SAV-1 and chelating dispersant SAV-2 of high temperature multichelating acid could eliminate sulfate scale, whose mechanisms are lattice distortion, chelating solubilization, and electrostatic interaction.

(5) Multichelating acid effectively inhibits the formation of secondary precipitation of fluosilicate, silica gel, and so forth, whose mechanisms are the surface properties' change and dispersion effect on silicon polymers by the effect of SAV2 and SAV-1. Since the chelating solubilization of multichelating acid system can inhibit the precipitation of $\mathrm{CaF}_{2}$, potential secondary damage can be eliminated effectively during acid treatment.

\section{Conflict of Interests}

The authors declare that there is no conflict of interests regarding the publication of this paper.

\section{Acknowledgments}

The authors wish to thank the management of Southwest Petroleum University and PetroChina Changqing Oilfield Company, for their permission to publish this paper and their assistance in applying these new techniques. Thanks are also to Lu Zhang and Zhi Li for their help with paper.

\section{References}

[1] E. P. da Motta, B. Plavnik, R. S. Schechter, and A. D. Hill, "Accounting for silica precipitation in the design of sandstone acidizing," SPE Production and Facilities, vol. 8, no. 2, pp. 138$144,1993$.

[2] E. C. Shuchart and R. D. Gdanski, "Reducing aluminum compound precipitation following subterranean formation acidizing," U.S. Patent no. 6,531,427, 2003.

[3] R. L. Thomas, H. A. Nasr-El-Din, J. D. Lynn, and S. Mehta, "Precipitation during the acidizing of a HT/HP illitic sandstone reservoir in eastern saudi arabia: a laboratory study," in Proceedings of the SPE Annual Technical Conference and Exhibition, Society of Petroleum Engineers, pp. 3239-3254, October 2001.

[4] S. A. Ali, C. W. Pardo, Z. Xiao et al., "Effective stimulation of high-temperature sandstone formations in East Venezuela with a new sandstone acidizing system," in Proceedings of the SPE
International Symposium and Exhibition on Formation Damage Control, Society of Petroleum Engineers, 2006.

[5] N. Kume and R. van Melsen, "New HF acid system improves sandstone matrix acidizing success ratio by $400 \%$ over conventional mud acid system in Niger Delta Basin," in Proceedings of the SPE Annual Technical Conference and Exhibition, SPE 56527, 1999.

[6] M. W. Bodine Jr. and T. H. Fernalld, "Edta dissolution of gypsum, anhydrite, and Ca-Mg carbonates," Journal of Sedimentary Research, vol. 43, no. 4, pp. 1152-1156, 1973.

[7] T. N. Tyler, R. R. Metzger, and L. R. Twyford, "Analysis and treatment of formation damage at Prudhoe Bay, Alaska," Journal of Petroleum Technology, vol. 37, no. 7, pp. 1010-1018, 1985.

[8] M. A. Sayed, H. A. Nasr-Ei-din, and C. A. de Wolf, "Emulsified chelating agent: evaluation of an innovative technique for high temperature stimulation treatments," in Proceedings of the SPE European Formation Damage Conference and Exhibition, pp. 385-404, Society of Petroleum Engineers, June 2013.

[9] B. G. Al-Harbi, N. M. Al-Dahlan, and M. H. Al-Khaldi, "Evaluation of chelating-hydrofluoric systems," in Proceedings of the International Petroleum Technology Conference (IPTC '13), 2013.

[10] G. D. Dean, C. A. Nelson, S. Metcalf, R. Harris, and T. Barber, "New acid system minimizes post acid stimulation decline rate in the Wilmington Field, Los Angeles County, California," in Proceedings of the SPE Western Regional Meeting, SPE-46201MS, Bakersfield, Calif, USA, May 1998.

[11] M. A. Mahmoud, A. H. Nasr-El-Din, C. de Wolf, J. N. LePage, and J. H. Bemelaar, "Evaluation of a new environmentally friendly chelating agent for high-temperature applications," in Proceedings of the International Symposium and Exhibiton on Formation Damage Control. Society of Petroleum Engineers (SPE '10), Lafayette, La, USA, February 2010.

[12] J. N. LePage, C. A. de Wolf, J. H. Bemelaar, and H. A. Nasr-ElDin, "An environmentally friendly stimulation fluid for hightemperature applications," SPE Journal, vol. 16, no. 1, pp. 104110, 2011.

[13] W. Frenier, M. Rainey, D. Wilson, D. Crump, and L. Jones, "A biodegradable chelating agent is developed for stimulation of oil and gas formations," in Proceedings of the SPE/EPA/DOE Exploration and Production Environmental Conference, SPE80597-MS, Society of Petroleum Engineers, San Antonio, Tex, USA, March 2003.

[14] W. Frenier, D. Wilson, D. Crump et al., "Use of highly acidsoluble chelating agents in well stimulation services," in Proceedings of the SPE Annual Technical Conference and Exhibition, Society of Petroleum Engineers, 2000.

[15] M. A. Mahmoud, H. A. Nasr-El-Din, C. A. de Wolf, and A. K. Alex, "Sandstone acidizing using a new class of chelating agents," in Proceedings of the International Symposium on Oilfield Chemistry, Society of Petroleum Engineers, pp. 1-17, April 2011.

[16] A. H. A. Ali, W. W. Frenier, Z. Xiao, and M. Ziauddin, "Chelating agent-based fluids for optimal stimulation of high-temperature wells," in Proceedings of the SPE Annual Technical Conference and Exhibition, Society of Petroleum Engineers, 2002.

[17] S. A. Ali, E. Ermel, J. Clarke, M. J. Fuller, Z. Xiao, and B. P. Malone, "Stimulation of high-temperature sandstone formations from West Africa with chelating agent-based fluids," SPE Production and Operations, vol. 23, no. 1, pp. 32-38, 2008.

[18] L.-M. Zhang, "Type for hydrofluoric acid dissolution effect of montmorillonite clay," Drilling Fluid and Completion Fluid, vol. 10, no. 5, pp. 28-32, 1993. 
[19] L.-M. Zhang, "Effect of hydrochloric acid in mud acid through sandstone acidizing," Oil Drilling \& Production Technology, vol. 16, no. 6, pp. 51-57, 1994.

[20] S.-G. Zhang, Theoretical study on the operation mechanism of scale and corrosion inhibitors [Ph.D. thesis], 2006.

[21] C.-W. Cui, S.-F. Li, H. Yang et al., "Study of corrosion inhibitors PBTCA, HEDP and ATMP," Materials Science \& Technology, vol. 14, no. 6, pp. 605-611, 2006.

[22] Y. Q. Zheng, E. W. Shi, W. J. Li, B. G. Wang, and X. F. Hu, "Research and development of the theories of crystal growth," Journal of Inorganic Materials, vol. 14, no. 3, pp. 321-331, 1999.

[23] Y.-X. Yang, X-Ray Diffraction Analysis, Shanghai Jiao Tong University Press, 1989.

[24] T.-S. Li, Foundation of Crystal X-ray Diffraction Study, Metallurgical Industry Press, 1990.

[25] N. M. Min, Physical Foundation of Crystal Growth, Shanghai Science Technology Press, 1982.

[26] J. Li and Z.-Y. Lin, "A Study on Scale Inhibiting Mechanism of HEDP Based on Molecule Simulation," Journal of Tongji University (Science and Technology), vol. 34, no. 4, pp. 518-522, 2006.

[27] Y.-X. Cao, J. Yang, and J. Li, "Study of inhibition HEDP and PBTCA," Journal of Tongji University, vol. 32, no. 4, pp. 556-560, 2004.

[28] L.-J. Yang, Y.-X. Zhang, and Y.-H. Huang, "Effect of scale inhibitor-dispersant on the crystallization of potassium (sodium) fluosilicate," Chemical Industry and Engineering, vol. 19, no. 1, pp. 1-5, 2002.

[29] Y. Lin-jun and Z. Yun-xiang, "Kinetics of growth of potassium (Sodium) fluosilicate crystal," Chemical Engineering, vol. 30, no. 2, pp. 15-18, 2002.

[30] G.-N. Feng, Y.-E. Chen, H.-L. Zhu, Y.-Q. Li, R. Zu, and H.Q. Tang, "An improvement in complexometic titration for evaluating the efficiency of scale inhibitors," Oilfield Chemistry, vol. 21, no. 3, pp. 284-286, 2004. 

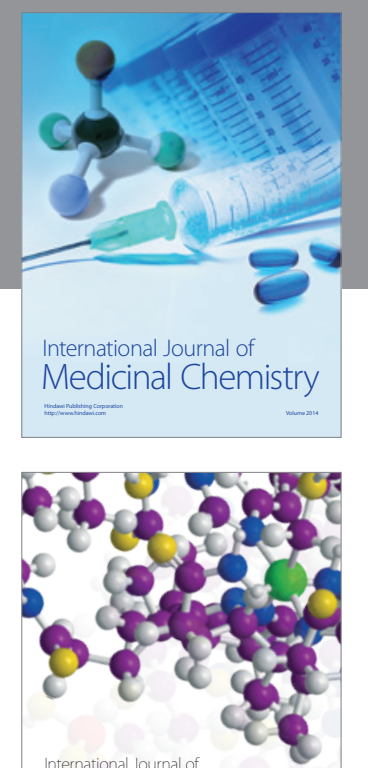

\section{Carbohydrate} Chemistry

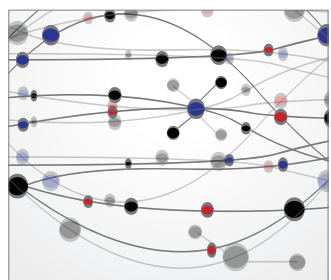

The Scientific World Journal
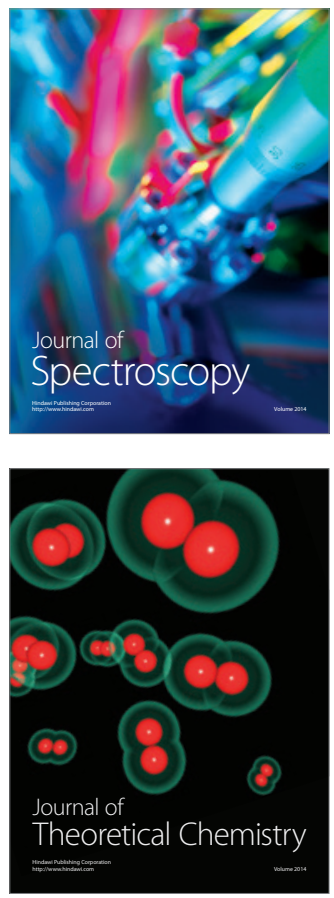
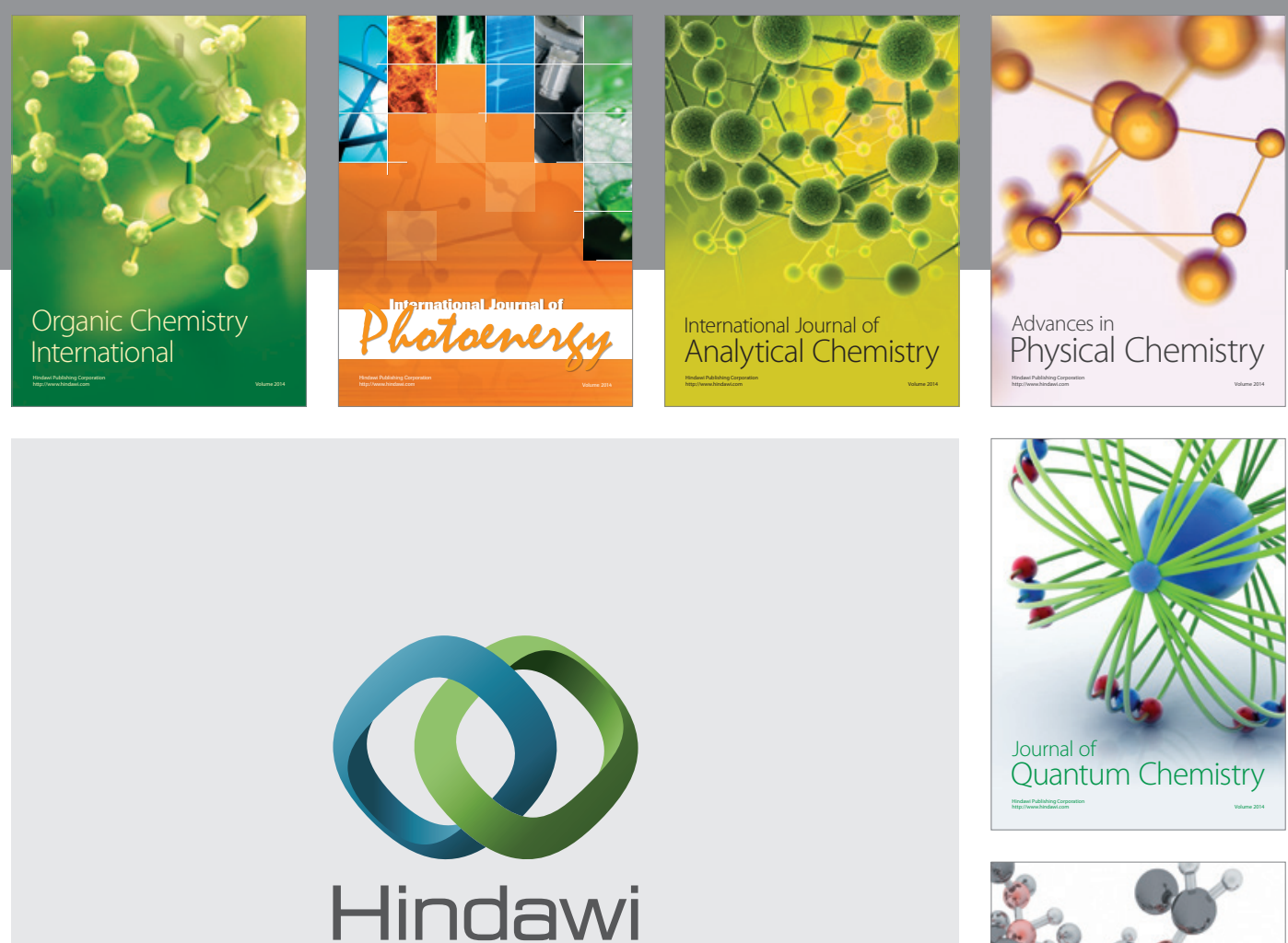

Submit your manuscripts at

http://www.hindawi.com

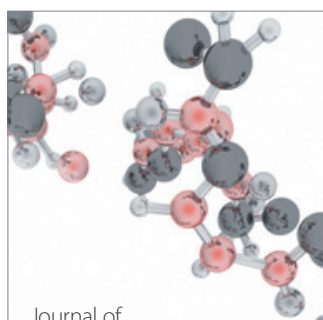

Analytical Methods

in Chemistry

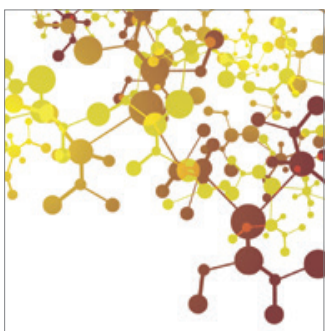

Journal of

Applied Chemistry

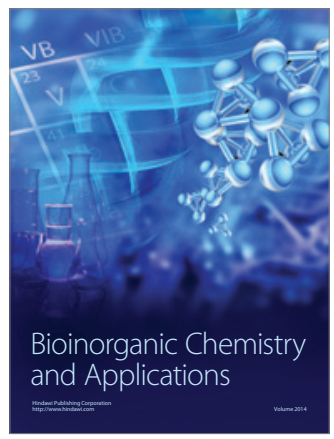

Inorganic Chemistry
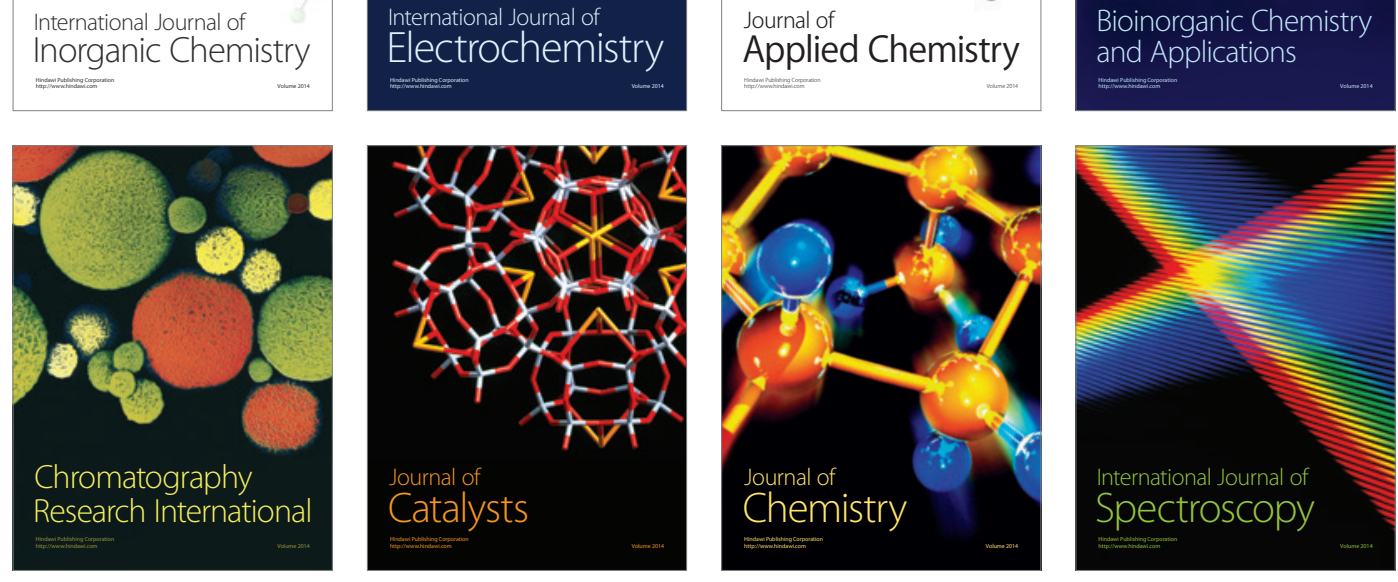